\title{
THE VISIBILITY OF PAPERS WRITTEN BY AUTHORS FROM EUROPEAN POST-SOCIALIST COUNTRIES AS AN INDICATOR OF INTEGRATION INTO THE EU LEGAL SYSTEM*
}

\author{
Dora Zgrabljić Rotar, Maja Jokić, Stjepan Mateljan**
}

Summary: The equality of the European Union (EU) Member States is one of the principles that the European Union is based on. However, in terms of the economy, culture and influence, a hierarchy of EU Members States is evident. The European post-socialist or Central and East European (CEE) countries are often perceived as being at the lower end of the scale or on the 'periphery' of the EU. The aim of this paper is to gain insights into the specificities of the CEE countries' legal scientific communication and the visibility of legal scholars' work within the EU. Bibliometric analysis results show that scientific productivity has been significantly contributed to by papers published in domestic journals indexed in Scopus, with a share of 70\%, and that the largest contributions are from Croatian, Romanian, Slovenian and Hungarian law journals. The Baltic States and EU candidate countries, representing nine out of 15 CEE countries, did not have their law journals indexed by Scopus in the period 1996-2013, which influenced their potential accessibility and visibility. The remaining 30\% of papers were scattered over 112 international law journals, predominantly from the EU15 countries. On the other hand, the research shows that the recognition of papers measured in terms of the average number of citations speaks in favour of publication in international journals, with $2.9 \mathrm{ci}$ tations per paper compared to 1.2 in domestic journals. It also shows that the citation of a paper is influenced by the language of the text and whether the paper has more than one author. Thus, although the vast majority of papers are published in domestic journals, the ones published in international journals are distinctly more visible in the academic community. In order to accomplish the integration of CEE countries into EU academic legal communication, the visibility of CEE countries' legal scholars' work is crucial. According to the analysis of this research, to achieve visibility, CEE countries' legal scholars should

\footnotetext{
This work has been supported by the Croatian Science Foundation as part of the IP-092014-9351 project. DOI: 10.3935/cyelp.14.2018.304.

** Dora Zgrabljić Rotar, Assistant Professor, Faculty of Law, University of Zagreb, https:// orcid.org/0000-0002-6558-4532; Maja Jokić, Senior Scientist, Institute for Social Research in Zagreb, https://orcid.org/0000-0002-0344-0904; Stjepan Mateljan, Assistant, Institute for Social Research in Zagreb.
} 
publish more in a lingua franca, which nowadays means English. The other possible way is to enhance the visibility and strengthen the position of scientific journals published in CEE countries by accepting professional journal standards. Needless to say, the aspect of the content and issues explored and published is also crucial.

\section{Introduction}

Scientific communication in the field of law is specific even when compared to other fields in the social sciences and humanities. Law is primarily a national discipline with an inherent impact on practice and upon which practical influences in turn have an impact. This fact remains true even in the context of European integration, since, even though the EU has vast legislative rights and, notwithstanding the principle of the primacy of European law, a significant part of legal issues remain in the hands of national legislators. Moreover, European law is predominantly applied by national courts and national practitioners. Thus, publications on national topics in the native language are more common than in other academic fields and areas of legal research, and even when published in international journals, papers still tend to be related to local topics, whether national or regional.

To some extent, however, within European legal scholarship, there has been a shift towards 'European' and 'global' topics, which has made the field more coherent. Some authors claim that CEE countries have remained on the periphery of this change. ${ }^{1}$ The fact that CEE countries share a peripheral destiny can be argued by pointing out their 'weaker industry and less efficient agricultural sector. ${ }^{2} \mathrm{CEE}$ countries have even been depicted as not overly EU-friendly, especially in the context of the decisions of their constitutional courts, which according to some legal scholars have the primary goal of protecting sovereignty. ${ }^{3}$

The purpose of this paper is to research the visibility of published scientific papers in the field of law in CEE countries as a potential indicator of integration into the EU academic space. The visibility and specificities of the academic communication of legal experts in CEE countries are analysed through publishing patterns in scholarly journals, in particular through the status of journals, authorship, the language of the papers, and the impact of published papers through citation analysis.

${ }^{1}$ D Kukovec, 'Law and the Periphery' (2015) 21 European Law Journal 406; R Manko, M Škop and M Štepanikova, 'Carving out Central Europe as a Space of Legal Culture: A Way Out of Peripherality?' (2016) 6 Wroclaw Review of Law, Administration \& Economics 4.

${ }^{2}$ Kukovec (n 1) 409.

${ }^{3}$ A Albi, 'Erosion of Constitutional Rights in EU Law: A Call for "Substantive Co-operative Constitutionalism”" [2015] Vienna Journal of International Constitutional Law 151, 152. 
Apart from its theoretical contribution to the understanding of the development of legal science in this group of European countries, the research can have a significant impact on the evaluation of scientific work, as well as on the decision-making process in CEE countries' respective academic research policies. This is because the systems of evaluating academic work are often not sophisticated enough to apply different criteria to different fields. Often, the same criteria are applied in a very broadly defined field, such as the social sciences, although different fields within the social sciences have significantly different dynamics in terms of research, methodology and paradigms of scientific communication.

This research is part of a larger bibliometric approach to research on the specificities of academic communication in legal science in authors from European post-socialist countries in the European Union. Significantly broader research is being conducted as part of the 'Research activity, collaboration and orientation in social sciences in Croatia and other post-socialist European countries (RACOSS) ${ }^{4}$ project, which is funded by the Croatian Science Foundation. The other aspects of this research in the field of legal science will be a co-citation analysis and social network analysis of authors, and a content analysis of published papers.

This research focuses on papers published in the period from 1996 to 2013 in legal journals indexed in Scopus, whose authors are from one of the 15 European post-socialist or Central and Eastern European countries (CEE countries). The CEE group of countries consists of 11 countries that are Member States of the European Union and four former Yugoslav countries that are EU candidate states, and which all share the same socialist past.

The CEE countries' legal backgrounds are, due to the inherent characteristics of their political systems, to some extent similar. These similarities derive from at least four different points: first, a shared socialist past; second, constitutional specificities as opposed to the wholesale reception of Western European legal models after 1989; third, their methodological identity; fourth, the similar languages of the region. ${ }^{5}$

This leads to the conclusion that CEE countries could have something in common in terms of research and academic communication in the field of legal science. The accession process and the implementation of the acquis communautaire was a challenge to post-socialist countries. However, the principle of equality of the EU Member States is one of the

\footnotetext{
${ }^{4}$ Research activity, collaboration and orientation in social sciences in Croatia and other post-socialist European countries (RACOSS) - IP-09-2014-9351 <http://racoss. idi.hr/index_en.html> accessed 4 December 2018.

${ }^{5}$ Manko and others (n 1) 22-23.
} 
principles that the European Union is based on, and in order to achieve this it is important to integrate the CEE countries into EU scientific communication in the field of law. This research aims to contribute to a better understanding of this integration by exploring the specificities of the CEE countries' scientific communication in the field of law, as measured through a bibliometric analysis. We expect to obtain answers to questions about publishing dynamics, differences between publishing papers in domestic CEE journals and international ones, differences in citations, and also the importance of the languages in which the papers were written.

This paper is structured as follows. After an introduction, the authors position law within scientific fields in general, and point out that law has several specificities compared to other scientific fields. In addition, legal scholarship in CEE countries can further be distinguished from that in other EU Member States. Following this theoretical section, the authors present their methodology by describing how the research was conducted and what the obstacles and limitations of the research were. In the third part of the paper, the results of the research are presented. They show that visibility depends on three key aspects: publication in international journals, language and co-authorship. Finally, the authors provide certain conclusions and suggestions on how to enhance the visibility of CEE countries' authors' work.

\section{The specificities of academic communication in legal scholarship}

Globally, there is a continuing misunderstanding in the evaluation process when comparing research in the field of law with other social sciences and the humanities, and to an even greater extent, there is a misunderstanding when comparing the research and publication pattern in the field of law with that in STEM subjects.

This first emerged in the 1970 s and is still true today. ${ }^{6}$ Scholars in the social sciences, humanities and law are more inclined to publish their research in the form of books or book chapters, as opposed to articles in journals. However, almost all university rankings, including the ones based solely on bibliometric data, such as the Leiden Ranking, ignore books, book chapters and other non-journal sources, even in disciplines where they play a crucial role. On the other hand, forms of scientific communication are changing with the development of scientif-

\footnotetext{
${ }^{6}$ K Kousha and M Thelwall, 'Google Book Search: Citation Analysis for Social Science and the Humanities' (2009) 60 Journal of the American Society for Information Science and Technology 1537, 1539; J Gorraiz and others, 'Availability of Digital Object Identifiers (DOIs) in Web of Science and Scopus' (2016) 10 Journal of Informetrics 98, 98.
} 
ic disciplines. Thus, as underlined by some authors, it should be noted that 'due to the pressure exerted by national evaluation schemes, many researchers shift or have shifted from books to journal articles as their preferred dissemination channel (Research Information Network 2009)'?

Another specificity of law is the inconsistent way of classifying it in the classification of sciences. The way Member States of the European Union classify law within their respective classification systems for scientific disciplines is not coherent. The majority of Member States that have accepted the OECD Field of Science and Technology (FOS) ${ }^{8}$ classification, classify law as a social science. Some Member States classify law as a scientific field sui generis. Namely, Spain adopts a system of 'the social sciences and law'9 and the Netherlands one of 'the social sciences, the humanities and law'. ${ }^{10}$ The differences between the three different possible ways of classifying law - first, as a social science; second, as a part of the humanities; third, as an independent sui generis academic field - determine the specificities of academic communication and the evaluation of the scholarship most often measured through bibliometric analysis.

However, notwithstanding how we classify law as a scientific field, it is an unusual academic discipline where the impact of the scholarship can be measured through two types of citation analysis. The first one is the classic academic citation analysis available through the databases of academic literature common to all academic fields. The second one, specific to law, is court citation analysis. Court citation analysis includes the analysis of citations of primary and secondary authorities in court decisions. Primary sources are regulations, laws, acts or prior judicial decisions or awards, while secondary authorities include academic papers, books, etc. According to Smyth, citations of secondary authorities, especially law review articles, can serve as an indicator of the extent to which the courts take account of the policy implications and social context of their decisions. ${ }^{11}$ However, this needs to be treated with caution, since the citation of secondary sources is customary only in common law jurisdictions where the courts create precedents, while in civil law

\footnotetext{
${ }^{7}$ D Torres-Salinas, N Robinson-Garcia and J Gorraiz, 'Filling the Citation Gap: Measuring the Multidimensional Impact of the Academic Book at Institutional Level with PlumX' (2017) 113 Scientometrics 1371, 1371.

${ }^{8}$ Revised Field of Science and Technology (FOS) Classification in the Frascati Manual <www.oecd.org/sti/inno/38235147.pdf> accessed 7 December 2018.

9 Torres-Salinas and others (n 7) 1340.

10 T Van Leeuwen, 'Bibliometric Research Evaluations, Web of Science and the Social Science and Humanities: A Problematic Relationship?' [2013] Bibliometrie-Praxis und Forschung <2013-bibliometrie-pf.de> accessed 7 December 2018.

${ }^{11}$ R Smyth, 'Citing Outside the Law Reports' (2014) 18 Griffith Law Review 692, 695.
} 
systems courts usually cite only primary sources, most often legal texts or sometimes previous judicial decisions. ${ }^{12}$

Since citations are one of the most frequently used bibliometric indicators and act as a proxy for the impact, author, journal, academic discipline, institution or sometimes the whole country, it is important to mention that the history of citation indices (WoS) is linked to the US legal profession's Shephard's Citations, which began in 1873 as a way to track citations to cases. ${ }^{13}$ 'In a legal system that honours and relies on precedent, tracking citations is a core research task. ${ }^{14}$ According to Wouters, Hebrew law-related citation indices have been used for about 700 years. ${ }^{15}$

Productivity, alongside citation analysis, is a significant bibliometric aspect of scientific communication. Journals, as a medium of scientific communication and a form of publishing, play an important role in the field of law. Warren stresses that during the 1980s and 1990s there was a significant increase in the number of scholarly legal journals worldwide. ${ }^{16}$ The SCImago Journal Ranking ${ }^{17}$ statistical database, on the basis of data provided by Scopus, analytically monitors 571 legal journals from all over the world. Interestingly, at present 352 of them are published in Europe: 332 in Western Europe and 20 in Eastern Europe. Legal journals make up $10 \%$ of the total number of journals in the social sciences both in Europe and worldwide. The legal journals indexed in Scopus are selected journals that meet the criteria set by that database. Most European countries have a large number of legal journals that publish papers on legal issues. Based on data found in a database specialising in serial publications (Ulrichsweb), ${ }^{18}$ after reviewing and reclassifying the journals, we found that 15 countries from the sample publish 902 scientific journals on the social sciences. Of that number, 90 journals publish on legal topics, thus making up a total of $10 \%$ of all

\footnotetext{
${ }^{12}$ M Wind, 'Do Scandinavians Care about International Law? A Study of Scandinavian Judges' Citation Practice to International Law and Courts' (2016) 85 Nordic Journal of International Law 281.

13 T Eisenberg and MT Wells, 'Ranking Law Journals and the Limits of Journal Citation Reports' (2014) 52 Economic Inquiry 1301, 1302.

14 Eisenberg and Wells (n 13).

${ }^{15}$ Eisenberg and Wells (n 13), referring to P Wouters, 'Garfield as Alchemist' in B Cronin and HB Atkins (eds), The Web of Knowledge: A Festchrift in Honor of Eugene Garfield (Information Today 2000) 65.

${ }^{16}$ D Warren, 'Australian Law Journals: An Analysis of Citation Patterns' (1996) 27 Australian Academic \& Research Libraries 261.

${ }_{17}$ SCImago Journal Ranking on Law <www.scimagojr.com/journalrank.php?category $=3308 \&$ type $=\mathrm{j}>$ accessed 9 December 2018 .

${ }^{18}$ Ulrich's ${ }^{\text {TM }}$ Serials Analysis System is one of the most relevant international sources that tracks serial publications published worldwide <www.ulrichsweb.com/ulrichsweb/analysis/> accessed 9 December 2018.
} 
journals in the social sciences. This data also shows the importance of journals as a communication medium in the field of law.

Rumsey provides additional confirmation of the importance of journals and papers in the field of law, claiming that $59.1 \%$ of citations in her sample in 2005 referred to journal articles, while in the 1980s and '90s there was the same ratio in favour of books. ${ }^{19}$ Lowe and Wallace stress that 'one of the most common types of bibliometric studies of law reviews attempts to rank the influence of these materials, typically by considering frequency or other analysis of citations in scholarship or court opinions'. ${ }^{20}$

A literature review of bibliometric research in the field of law shows that US authors dominate this field. There is also a significant number of published papers by authors from Commonwealth countries, mostly from the UK, Australia and Canada. ${ }^{21}$ This confirms that this type of research has more often been conducted in countries with a common law tradition. The authors in these countries, apart from providing a comprehensive overview of literature, often provide a critical analysis as well. However, when measuring research performance, many existing studies focus on quantity without regard to the quality of publications. Second, most studies use only one measure of productivity, ie citations or publications. Third, many of the existing studies focus on staff drawn from a single university or only a few universities. ${ }^{22}$

This situation complicates a systematic overview of the relevant literature. Papers that deal with citation analysis and journal rankings dominate, which is most often for the purpose of law school rankings.

Warren provides a thorough literature overview until the mid-1990s of the twentieth century. ${ }^{23}$ The most common topic was research on the most frequently cited law reviews. ${ }^{24}$ The conclusion is that a small percentage of published titles are heavily cited and a small group of law reviews dominate legal scholarship. ${ }^{25}$

\footnotetext{
${ }^{19}$ M Rumsey, 'Gauging the Impact of Online Legal Information on International Law: Two Tests' (2008) 35 Syracuse Journal of International Law and Commerce 201, 210.

${ }^{20}$ MS Lowe and KL Wallace, 'HeinOnline and Law Review Citation Patterns' (2011) 103 Law Library Journal 55, 57.

${ }^{21}$ R Smyth and V Mishra, 'Academic Inbreeding and Research Productivity and Impact in Australian Law Schools' (2014) 98 Scientometrics 583.

22 Smyth and Mishra (n 21) 584.

${ }^{23}$ Warren (n 16) 261.

${ }^{24}$ Warren (n 16) 261.

${ }^{25}$ Warren (n 16) 269.
} 
Eisenberg and Wells made a significant contribution when they measured the USA's top 32 law schools' academic reputations by assessing the degree to which the major consumers of legal scholarship, ie legal academics, use the schools' scholarly output through citations to their faculties' works. ${ }^{26}$ Ayres and Vars published one of the first integral pieces of research in 2000. ${ }^{27}$ Aware of the fact that numerical data on citation speaks very little per se, they analysed the determinants of citations of articles in elite USA law reviews. ${ }^{28}$ The important determinants for the citation of articles are subject area, readership, number of authors, article placement in the journal (first placed articles generally receive more citations than articles appearing later), nepotism and elitism, gender status, etc. ${ }^{29}$ Black and Caron contributed further to the understanding of the role of citation in the ranking of journals and law schools. ${ }^{30}$ This research can be considered the first altmetrical ${ }^{31}$ approach to the issue of law school rankings. It was motivated by the shortcomings of the methodology used by the US News \& World Report (US News) in university rankings. In their research of article age as a variable that affects the likelihood of citation and its dependence on the availability of complete papers on HeinOnline, Lowe and Wallace made a significant contribution to the field. ${ }^{32}$ Their conclusion clearly shows that authors of law review articles remain far more likely to cite articles that have been published fairly recently. ${ }^{33}$ This is, however, consistent with the fact that law is a dynamic discipline, which often results in the fact that only recent studies are applicable and relevant to a certain legal topic or issue.

Shapiro and Pearse have made an important contribution towards the understanding of the citation analysis issue and the introduction of new methodological approaches. ${ }^{34}$ Moreover, according to Balkin and Levinson, Shapiro is considered the founding father of a new and distinct discipline: legal citology. ${ }^{35}$ Shapiro and Pearse used a multimethod

\footnotetext{
${ }^{26}$ Eisenberg and Wells (n 13) 373.

${ }^{27}$ I Ayres and FE Vars, 'Determinants of Citations to Articles in Elite Law Reviews' (2000) 29 Journal of Legal Studies 427.

${ }^{28}$ Ayres and FE Vars (n 27) 427.

${ }^{29}$ Ayres and FE Vars (n 27) 427.

${ }^{30}$ BS Black and PL Caron, 'Ranking Law Schools: Using SSRN to Measure Scholarly Performance' (2006) 81 Indiana Law Journal 83.

${ }^{31}$ What are Altmetrics? <www.altmetric.com/about-altmetrics/what-are-altmetrics/> accessed 9 December 2018.

${ }^{32}$ Lowe and Wallace (n 20) 55.

${ }^{33}$ Lowe and Wallace (n 20) 67.

${ }^{34}$ FR Shapiro and M Pearse, 'The Most-Cited Law Review Articles of All Time' (2012) 110 Michigan Law Review 1483.

35 JM Balkin and S Levinson, 'How to Win Cites and Influence People' (1996) 71 Chicago-Kent Law Review 843, 843.
} 
analysis to determine the characteristics of the top-ranked publications, authors, and law schools to show the trends in schools of legal thought. ${ }^{36}$ They investigated how alternative tools and metrics intersect with traditional citation studies and how they might affect legal scholarship in the future. ${ }^{37}$ The issue of ranking law schools and law school journals is a popular one, especially in the United States and other common law countries, mainly because their legal education is much more costly and the costs of studying in certain law schools depend predominantly on the school's ranking. Although research and publications on the ranking of law schools and the role of law journal rankings in the ranking of law schools are very popular, some authors have suggested that there are certain drawbacks to the popularity of these issues. ${ }^{38}$

Similar research has been far less popular in Europe. The most significant contribution has been made by van Gestel, who investigated the sense and non-sense of a European ranking of law journals and law schools. ${ }^{39}$ The first relevant research on the issue of ranking law journals was published by Campbell, Goodcare and Little in 2006. ${ }^{40}$ Although they primarily deal with the ranking of UK law journals, they do not focus on citation analysis but on a large-scale study measuring the perceptions of academic lawyers concerning the journal publishing process, how the Research Assessment Exercise (RAE) has affected journal quality generally, and how specific journals rank in terms of academic quality, and their perceived importance to the RAE process. ${ }^{41}$

Apart from citation analysis, other bibliometric indicators provide an insight into the development and specificities of certain academic disciplines, eg monitoring the development of journals. De Brabandere and Venzke problematise the position of the Leiden Journal of International Law and its role in the development of international law from multiple positions. ${ }^{42}$ Using the example of the $75^{\text {th }}$ issue of the Nordic Journal of

\footnotetext{
${ }^{36}$ Shapiro and Pearse (n 34) 1483.

${ }^{37}$ Shapiro and Pearse (n 34) 1483.

${ }^{38}$ T Eisenberg and MT Wells, 'Ranking and Explaining the Scholarly Impact of Law Schools' (1998) 27 Journal of Legal Studies 373; Smyth and Mishra (n 21); AL Brophy, 'Ranking Law Schools with LSATs, Employment Outcomes, and Law Review Citations' (2016) 91 Indiana Law Journal Supplement 55.

${ }^{39} \mathrm{R}$ van Gestel, 'Sense and Non-sense of a European Ranking of Law Schools and Law Journals' (2015) 35 Legal Studies 165.

${ }^{40} \mathrm{~K}$ Campbell, A Goodacre and G Little, 'Ranking of United Kingdom Law Journals: An Analysis of the Research Assessment Exercise 2001 Submissions and Results' (2006) 33 Journal of Law and Society 335.

${ }^{41}$ Campbell and others (n 40).

${ }^{42}$ E De Brabandere and I Venzke, 'The Activities of the Leiden Journal of International Law: Past, Present, and Future' (2016) 29 Leiden Journal of International Law 285; E De Brabandere and I Venzke, 'The Leiden Journal of International Law at 30' (2017) 30 Leiden Journal of International Law 1.
} 
International Law, Noll scrutinises the idea of the development of the journal through changing concepts, content and form, which could be regarded as having the status of a certain academic discipline. ${ }^{43}$

Analysis of the authorship of papers in law journals contributes to an understanding of the paradigm of scientific communication in the field of law as well. According to Ginsburg and Miles, academic collaboration rises with scholarly specialisation: ${ }^{44}$

Quantitative analysis has historically not been part of the legal curriculum, and even now, it is rare for a legal academic to have graduate training in these methods. A plausible prediction is that by virtue of its higher degree of specialization, interdisciplinary, and particularly empirical, work will more often be collaborative than general legal scholarship. ${ }^{45}$

George and Guthrie's research results show that about half of the articles in their sample were written in co-authorship. ${ }^{46}$ In the context of the importance of the papers published by foreign authors for a journal, Dimatteo finds that 'the breadth of subject matter and the diversity of its authors are the ingredients that make the Journal special.' ${ }^{47}$

Insights into legal research and the issues it deals with in each EU Member State are important for the European legal system, acquis communautaire and the integration of the European Union. Mudge and Vauchez investigated the European Union integration process specifically through legal research. ${ }^{48}$ They found that EU legal scholarship remains nationally segmented, ie that French law scholars predominantly publish in French law journals and German law scholars in German law journals. ${ }^{49}$ These data provided an incentive to carry out analogous research of papers published by legal experts from the $15 \mathrm{CEE}$ countries that are EU Member States or EU candidate countries. They show that CEE countries are not an isolated example of legal publications being predominantly in national journals and in national languages. This could

\footnotetext{
${ }^{43}$ G Noll, 'Editorial: The $75^{\text {th }}$ Issue of the Nordic Journal of International Law' (2006) 75 Nordic Journal of International Law 1.

${ }^{44}$ T Ginsburg and TJ Miles, 'Empiricism and the Rising Incidence of Co-authorship in Law' (2011) 5 University of Illinois Law Review 1785.

45 Balkin and Levinson (n 35) 1787.

${ }^{46}$ TE George and C Guthrie, 'Joining Forces: The Role of Collaboration in the Development of Legal Thought' (2002) 52 Journal of Legal Education 559.

47 LA Dimatteo, 'Fifty Years of Contract Law Scholarship in the American Business Law Journal' (2013) 50 American Business Law Journal 105, 151.

48 SL Mudge and A Vauchez, 'Building Europe on a Weak Field: Law, Economics, and Scholarly Avatars in Transnational Politics' (2012) 118 American Journal of Sociology 449.

49 Mudge and Vauchez (n 48) 462.
} 
support the claim that law is still predominantly a national discipline. It might also lead to the conclusion that the path to greater visibility for CEE countries' legal scholars' work in the EU does not exclusively lie in publication of their work in international journals in English but that a better path might be to strengthen the position of domestically published international journals.

\section{Sample and methodological approach}

Social sciences and humanities scholars are often suspicious when it comes to the application of quantitative research techniques, especially the use of bibliometric analysis of productivity and citation scores, in their research. Legal scholars are particularly sceptical, especially the legal academic community in smaller European countries. However, bibliometric analysis as a quantitative approach nevertheless provides a certain insight into the specificity of academic productivity and the visibility of published research results as one of the indicators of the integration of $\mathrm{CEE}$ countries into the EU academic community.

The main sources for bibliometric research are the citation databases Web of Science (WoS), ${ }^{50}$ Scopus $^{51}$ and Google Scholar. ${ }^{52}$ As far as law is concerned, of the three mentioned sources, it would be potentially optimal to select Google Scholar. We emphasise potentially optimal, because it includes in its corpus all types of publication (articles, chapters in books, books, etc) important for the field of law. However, this source still has no reliable capabilities for searching for data like those offered by professional databases such as WoS and Scopus, ${ }^{53}$ and the sample we analysed could not be extracted from Google Scholar. The WoS database is not a reliable source for research in the field of law, especially in the case of non-English speaking countries and small Central and Eastern European countries. Currently, WoS indexes 150 journals categorised under the field of law. All these publish papers exclusively in English, with journals from English-speaking countries dominating, and there are no CEE law journals.

\footnotetext{
${ }^{50}$ Clarivate Analytics, 'Web of Science' <https://clarivate.com/products/web-of-science/> accessed 29 November 2018.

${ }^{51}$ Elsevier, 'Scopus' <www.elsevier.com/solutions/scopus> accessed 29 November 2018.

${ }^{52}$ Google Scholar <https://scholar.google.com/intl/en/scholar/about.html> accessed 29 November 2018.

${ }^{53}$ A Martín-Martín, E Orduna-Malea, M Thelwall and E Delgado López-Cózar, 'Google Scholar, Web of Science, and Scopus: A Systematic Comparison of Citations in 252 Subject Categories (2018) 12(4) Journal of Informetrics 1160; FR Jensenius, M Htun, DJ Samuels, DA Singer, A Lawrence and M Chwe, 'The Benefits and Pitfalls of Google Scholar' (2018) 51(4) PS - Political Science and Politics 820.
} 
In this research, the Scopus database was chosen because it is the largest searchable citation and bibliographic source of literature for multidisciplinary scientific literature, ${ }^{54}$ and is continually expanded and updated, including retroactive inclusion of sources and citations. Since this research is only one segment of a more extensive investigation into research activity, collaboration and subject research orientation in the social sciences in Central and Eastern European countries, the optimal choice of the three mentioned sources was Scopus.

According to scholars, Scopus offers a thematically and regionally more balanced representation of journals, and possesses credible journal selection procedures and adequate bibliometric indicators. ${ }^{55}$ The 551 law journals currently indexed in Scopus provide confirmation of these claims. Of this number, 352 journals are published in Europe: 332 in Western Europe and 20 in Eastern Europe.

Grančay stresses that in recent times, Scopus has been the database that makes scholarship in CEE countries most visible in comparison with other international sources. ${ }^{56}$ In this research, an additional argument was that papers indexed in Scopus are relevant in career promotions as well as in international university rankings. Although we are aware of the shortcomings of university rankings ${ }^{57}$ for CEE countries, they have become important in the process of globalisation, and in some way are inevitable.

The best choice for all aspects of bibliometric research (productivity, citation analysis, authorship, social network analysis, content analysis,

\footnotetext{
$54 \mathrm{~J}$ Bar-Ilan, 'Which h-index? A Comparison of WoS, Scopus and Google Scholar' (2007) 74(2) Scientometrics 257; M Falagas, E Pitsouni, G Malietzis and G Pappas 'Comparison of PubMed, Scopus, Web of Science, and Google Scholar: Strengths and Weaknesses' (2008) 22(2) The FASEB Journal 338; J García, R Rodriguez-Sánchez and J Fdez-Valdivia, 'Ranking of the Subject Areas of Scopus' (2011)62(10) Journal of the American Society for Information Science and Technology 2013; A Chadegani, H Salehi, MD Yunus, M Farhadi and N Ale Ebrahim, 'A Comparison between Two Main Academic Literature Collections: Web of Science and Scopus Databases' (2013) 9(5) Asian Social Science 18.

55 É Archambault, D Campbell, Y Gingras and V Larivière, 'Comparing Bibliometric Statistics Obtained from the Web of Science and Scopus' (2009) 60 Journal of the American Society for Information Science and Technology 1320; E Abadal, R Melero, R Schwarz Rodrigues and M Navas-Fernández, 'Spanish Scholarly Journals in WoS and Scopus: The Impact of Open Access' (2015) 47(1) Journal of Scholarly Publishing 77; H Moed, M Aisati and A Plume, 'Studying Scientific Migration in Scopus' (2012) 94(3) Scientometrics 929.

${ }_{56}$ M Grančay, J Vveinhardt and Ẽ Šumilo, 'Publish or Perish: How Central and Eastern European Economists Have Dealt with the Ever-increasing Academic Publishing Requirements 2000-2015' (2017) 111(3) Scientometrics 1813.

${ }^{57}$ M Jokić and I Petrušić, 'Neki od uzroka slabe zastupljenosti hrvatskih sveu ilišta na svjetskim rang ljestvicama sveučilišta' [Some of the Reasons for the Poor Representation of Croatian Universities in World University Rankings] (2016) 22(1) Medijska istraživanja [Media Research] 5.
} 
etc) in the field of law could be a subject-oriented bibliographic, citation and full text database. If, for example, the Heinonline database had the opportunity for citation analysis, then it would be the most relevant source for bibliometric research in the field of law. However, since that is not the case, Scopus was the best solution for this particular research.

The sample in this research consists of 1,336 papers, published in 116 journals in the field of law, and indexed by Scopus in the period from 1996 until 2013. ${ }^{58}$ This sample (representing only a share of $3.76 \%$ ) is an integral part of the RACOSS project database, which after detailed reviewing and refining comprises 35,651 bibliographic records of articles and reviews published in social science journals by authors with an address from one of the $15 \mathrm{CEE}$ countries. The 116 journals were divided into two groups, depending on the publisher's country. The first group was called 'domestic journals' or 'CEE journals', and covered all the journals published in the CEE countries. This group consists of 12 journals and published a total number of 927 papers or $69 \%$ of all the papers that make up our research sample. The journals are divided into two groups because we assume that there is a significant difference in the visibility of papers as measured by citations. The other group of journals is named 'international journals', and this group consists of 104 journals that published a total of $31 \%$ of the papers in our research sample. Each paper has at least one author with an address in one of the $15 \mathrm{CEE}$ countries: the 11 EU Member States (Bulgaria, Croatia, Czech Republic, Estonia, Hungary, Latvia, Lithuania, Poland, Romania, Slovakia and Slovenia) and the $4 \mathrm{EU}$ candidate countries (Bosnia and Herzegovina, Macedonia, Montenegro and Serbia).

It is important to mention that during the period of data extraction for the research, Scopus had as a default an option to limit searches in the main subject field called the social sciences and humanities (SSH), and that option was used. Together with this option, search limitations included the period of time (1996-2013), author affiliation and country, and document type (article or review), which altogether resulted in a data-

\footnotetext{
${ }^{58}$ The period (1996-2013) for which the bibliographic data was collected is related to the application for the project. Namely, we applied for the project in 2014, and the financing was granted in 2015. Thus, in the project application the latest integral year for data collection was 2013. We started with 1996 because that is the year from when Scopus data is available. The biggest problem with amending the data, ie prolonging the period to 2016, would be the unreliability of the information collected in Scopus. Namely, the clearing and checking, together with the reclassification of the bibliographic data, lasted two years. In the meantime, Scopus changed its default search engine options. For additional information, visit the Institute for Social Research in Zagreb, 'RACOSS' <http://racoss.idi.hr/index_en.html> accessed 8 December 2018.
} 
set of 83,059 bibliographic records. Since the focus of the research was limited to the social sciences, it was necessary to reclassify the obtained dataset which had been collected for the social sciences and humanities. For the purpose of this research, we used the Croatian Classification of Sciences, which is based on the OECD Frascati Field of Science (FOS) classification, which contains the following academic fields: economics and business, educational sciences, library and information sciences, law, political science, psychology, sociology, and three multidisciplinary fields: the social sciences, the social sciences and humanities, and the social sciences and other fields.

An additional problem in obtaining a reliable research dataset was the incoherence in the classification of law as a science, which is discussed earlier in this text. As mentioned, some countries classify law as a part of the social sciences, some as a part of the humanities, and some countries as an independent sui generis academic discipline. Thus, this research began with the social sciences and humanities dataset, which consisted of 83,059 papers published in 4,896 journals, which were highly likely to include law articles as well.

Reviewing each paper to classify the dataset was not a solution with such a large sample. The problem was solved by checking and reclassifying all 4,896 journals, which is, in essence, the same solution used by all relevant databases. After the social science experts had checked and reclassified the journals, the final dataset of social science journals consisted of 2,726 with 35,501 papers. The law experts defined the final sample for this research, based on their knowledge of the journals and a review of the journals' subject orientation. The final number of legal journals was 116, with 1,336 published papers. We are aware of the possibility that some papers have been left out of this sample simply because they were published in a journal that is not primarily a legal one. We will try to identify and define this potential limitation in one of our following pieces of research. We use the term 'potential limitation' intentionally, because the papers covering legal issues which are published in journals that primarily cover another academic field can be indicators of the development of interdisciplinarity in law.

Since the project is focused on the research of status and visibility, as well as certain indicators of the integration process in the social sciences in European post-socialist countries, including in law, we chose Scopus as the most appropriate multidisciplinary source of data. We consider Scopus to be more appropriate than WoS, for example, because it covers a larger number of journals, particularly European journals. Other authors agree that Scopus has a balanced thematic and regional representation of journals, credible journal selection procedures, and 
adequate bibliometric indicators. ${ }^{59}$ We have also taken into account the important fact that Scopus papers are relevant in terms of academic career advancement and world university rankings.

Given the purpose of this research, we concentrated on the following analyses: productivity and the citation of papers, the type of journal in which the paper is published (ie whether it is a domestic journal or international journal), ${ }^{60}$ authorship and the language of published and cited papers. Analyses have been carried out on the total sample $(\mathrm{N}=1,366)$ and comparatively on the sample of grouped countries for the period from 1996 until 2013. The data was collected at the beginning of 2015 and includes citations from that year.

The countries have been grouped into three groups depending on the time of their accession to the European Union. The grouping of countries according to the year of their accession is important because countries had certain obligations concerning the common science policy to fulfil before accession. Group A consists of the eight countries that became Member States in 2004 (Czech Republic, Estonia, Hungary, Latvia, Lithuania, Poland, Slovakia and Slovenia), Group B consists of the three countries that became Member States during the period from 2007 until 2013 (Bulgaria, Croatia and Romania), while Group C consists of EU candidate countries (Bosnia and Herzegovina, Macedonia, Montenegro and Serbia) which are currently in different stages of accession negotiations but are important for this research since they are all former Yugoslav post-socialist countries.

This research aims to show at least some signs of visibility and integration of CEE countries into the EU legal academic research field, as well as to find a new way to integrate CEE countries into the EU.

\section{Results and discussion}

The primary indicator of potential visibility in a certain scientific field is, from a bibliometric standpoint, productivity, ie the number of published papers. Thus, in the first part of the research, we measured the total number of published papers in CEE countries in the period 1996-2013.

\footnotetext{
59 Archambault and others (n 55) 1320; S Miguel, Z Chinchilla-Rodriguez and F De MoyaAnegón, 'Open Access and Scopus: A New Approach to Scientific Visibility from the Standpoint of Access' (2011) 62(6) Journal of the American Society for Information Science and Technology 1130; DJ Solomon, 'Types of Open Access Publishers in Scopus' (2013) 1 Publications 16; Z Chinchilla-Rodríguez, S Miguel and F De Moya-Anegón, 'What Factors Affect the Visibility of Argentinean Publications in Humanities and Social Sciences in Scopus? Some Evidence Beyond the Geographic Realm of Research' (2015) 102 Scientometrics 789.
}

${ }^{60}$ As defined above. 
Figure 1 shows the distribution of the number of published papers in the total sample of $15 \mathrm{CEE}$ countries by group of countries. The first significant increase in the dynamics of scientific productivity in the total sample of 15 CEE countries occurred in 2005, which could be a consequence of the accession to the EU of the countries in Group A. The same argument could be applied for the countries in Group B in the year 2008 as a consequence of the accession of Romania and Bulgaria.

Figure 1 Distribution of the number of papers in the period 1996-2013 in the total sample and by group of countries

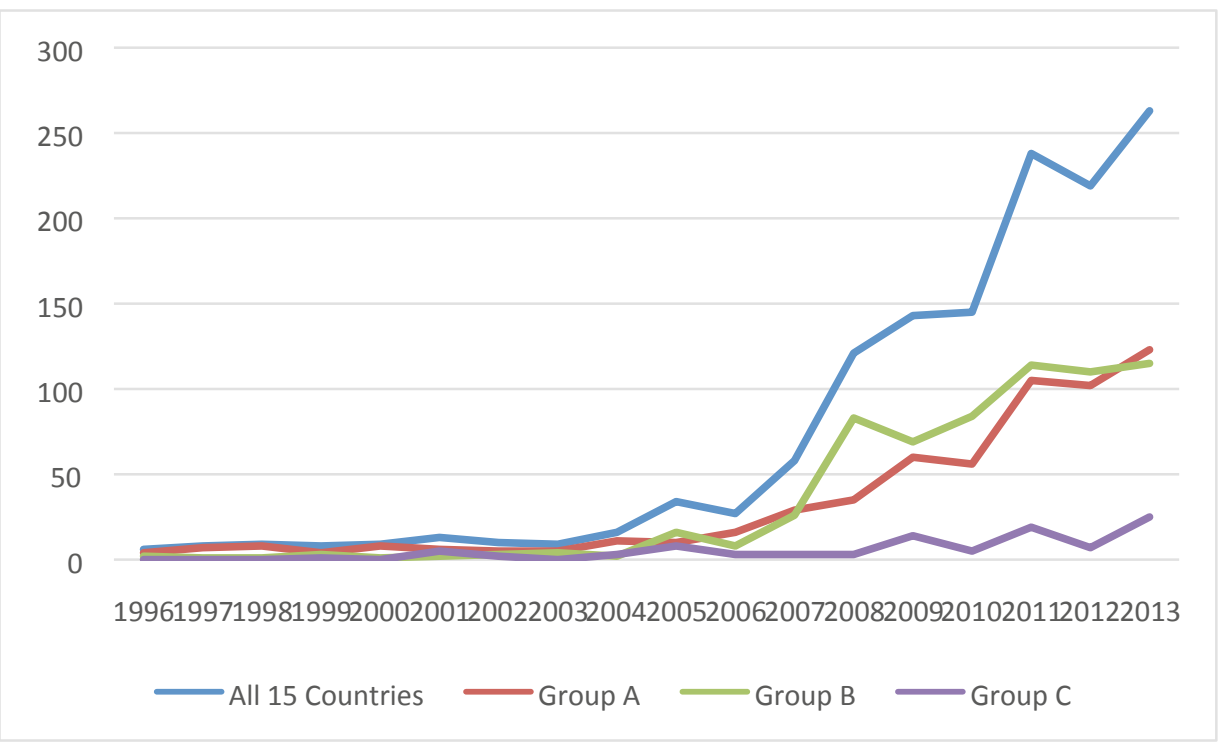

A more precise explanation of the increase in the number of published papers after 2005 is directly related to the indexing of CEE legal journals in the Scopus database. Although only 20\% of the journals of the total sample of CEE countries are entered in Scopus, these journals were the ones in which approximately $70 \%$ of papers were published. The year 2004 is also significant in terms of the increase, since this was the year of the greatest enlargement of the EU, with the accession of eight countries, which in our research are marked as Group A. Moreover, in 2004 Croatia became an EU candidate country, and in 2005 both Romania and Bulgaria signed their treaties on accession. Thus, the year 2005 was a significant moment for $\mathrm{CEE}$ countries and their integration into the EU, which evidently had an impact on published legal research and indexed legal papers. 
According to the Ulrichsweb database,${ }^{61} \mathrm{CEE}$ countries have a total number of 90 journals that publish on law-related topics. This number is distributed across $11 \mathrm{CEE}$ countries, leaving four of them without a domestic legal journal. Only 12 of the journals are indexed in Scopus and distributed across six of the 11 countries with legal journals (Table 1).

Table 1 Number of CEE country domestic law journals covered by the Ulrichsweb and Scopus databases

\begin{tabular}{|l|l|c|c|}
\hline \multicolumn{2}{|c|}{ Journal publisher's country } & Ulrichsweb & Scopus / No of papers \\
\hline \multirow{4}{*}{ Group A } & Poland & 28 & $1 / 30$ \\
\cline { 2 - 4 } & Czech Republic & 18 & $1 / 5$ \\
\cline { 2 - 4 } & Slovenia & 5 & $3 / 141$ \\
\cline { 2 - 4 } & Slovakia & 3 & \\
\cline { 2 - 4 } & Lithuania & 2 & \\
\cline { 2 - 4 } & Hungary & 1 & $1 / 109$ \\
\hline \multirow{3}{*}{ Group B } & Romania & 16 & $2 / 182$ \\
\cline { 2 - 4 } & Croatia & 5 & $4 / 460$ \\
\hline \multirow{3}{*}{ Group C } & Serbia & 8 & \\
\cline { 2 - 4 } & Bosnia \& Herzegovina & 3 & \\
\cline { 2 - 4 } & Montenegro & 1 & \\
\hline \multirow{2}{*}{ Total } & \multicolumn{2}{|c|}{$\mathbf{9 0}$} & $12 / 927$ \\
\hline
\end{tabular}

On the other hand, Croatia and Slovenia have an above average number of indexed journals. The reasons for the low number of CEE law journals indexed in Scopus (Table 1) has yet to be researched. A potentially important reason might be the issue of editorial policy and the quality of papers. Although we are aware that Scopus is not the most important secondary literature source in the field of law, it is the most representative international multidisciplinary citation database. If the journals are not represented in such a source, the chances of the visibility of published papers are smaller. On the other hand, the representation of the journal in a given database represents only a chance that the papers will be noticed by the relevant academic and professional community. What makes a paper visible and what is measurable is its citation. We are aware that visibility, which is usually measured by the number of citations received, is a very complicated issue and highly dependent on the specifics of scientific communication within a particular field, as well as on human factors.

${ }^{61}$ UlrichsWeb is a database of journals and is useful for identifying journals in a subject area, and checking if they are peer reviewed and in what database they are indexed or available in full text. UlrichsWeb is the authoritative source of bibliographic and publisher information on more than 300,000 periodicals of all types, including academic and scholarly journals. UlrichsWeb: Global Serials Directory <http://flinders.libguides.com/ research_tools/ulrichs> accessed 30 November 2018. 
However, these issues are complex and require a multi-methodological approach, and so could not be included in this research.

The data in Figure 1 and Table 1 clearly show which of the groups of countries and which particular countries have considerably contributed to the increase in the number of papers published in domestic journals. The countries in Group B, despite having only six journals indexed in Scopus, as do the countries in Group A, have a significantly higher number of indexed papers. In this research, we have not explored the reasons why the two groups of countries, despite having an equal number of journals, have a difference in the number of published papers. The possible reasons include the selectivity of Scopus in its choice of papers, the selection of types of papers, the time span of indexed journals, etc.

The papers published in Croatian, Romanian, Slovenian and Hungarian domestic legal journals dominate the total sample. It is important to notice that the Baltic States and EU candidate countries did not have any domestic legal journals indexed in Scopus in the period 1996-2013. From a practical perspective, the legal scholars of nine CEE countries do not even have the option of the potential visibility of their papers, since their domestic legal journals were not included in the most relevant multidisciplinary source of the international exchange of ideas. On the other hand, papers published in the domestic legal journals of four countries (Croatia, Romania, Slovenia and Hungary) made up 98\% of the Scopus database.

The fact that the vast majority of papers indexed in Scopus are published in domestic journals can be explained by the fact that law is, notwithstanding the common EU legal system, and the acquis communautaire, still predominantly a national discipline. This is because there are many legal issues in the EU that are still left to the national legislator. A second reason is because all legal rules, even those in European Regulations, are most often applied by national courts making the most of national case law. Finally, there is a real need to publish in the national language and in a national journal that is easily available and understandable to legal practitioners, notwithstanding whether the paper is published on a matter of national law or one of European law.

In line with these reasons, our research analysis of the addresses of the authors in CEE legal journals confirms that over 99\% of papers are published in the author's country. This result is similar to the results acquired by Mudge and Vauchez ${ }^{62}$ in their research on the development of EU integration in the field of law. The authors found that EU legal scholarship remains nationally segmented, ie that French law scholars

62 Mudge and Vauchez (n 48) 460. 
predominantly publish in French law journals and German law scholars in German ones. ${ }^{63}$ Similar results were acquired by Black and Caron on a research sample of US papers and the preference for publishing in home school journals. ${ }^{64}$

Ananalysis of scientific productivity in the period 1996-2005(Figure 2) shows a somewhat more pronounced trend towards publication in international journals compared to domestic CEE journals. The reason for this is that in this initial period domestic journals were not indexed in Scopus. Although after 2005 the number of CEE law journals in Scopus rose, the trend of publishing in international journals increased significantly and around 90\% of papers were published in international journals. Figure 2 shows the changes in the dynamic of publishing in international and domestic journals in the period 1996-2013.

Figure 2 Distribution of the number of papers in domestic and international journals in the total sample in the period 1996-2013

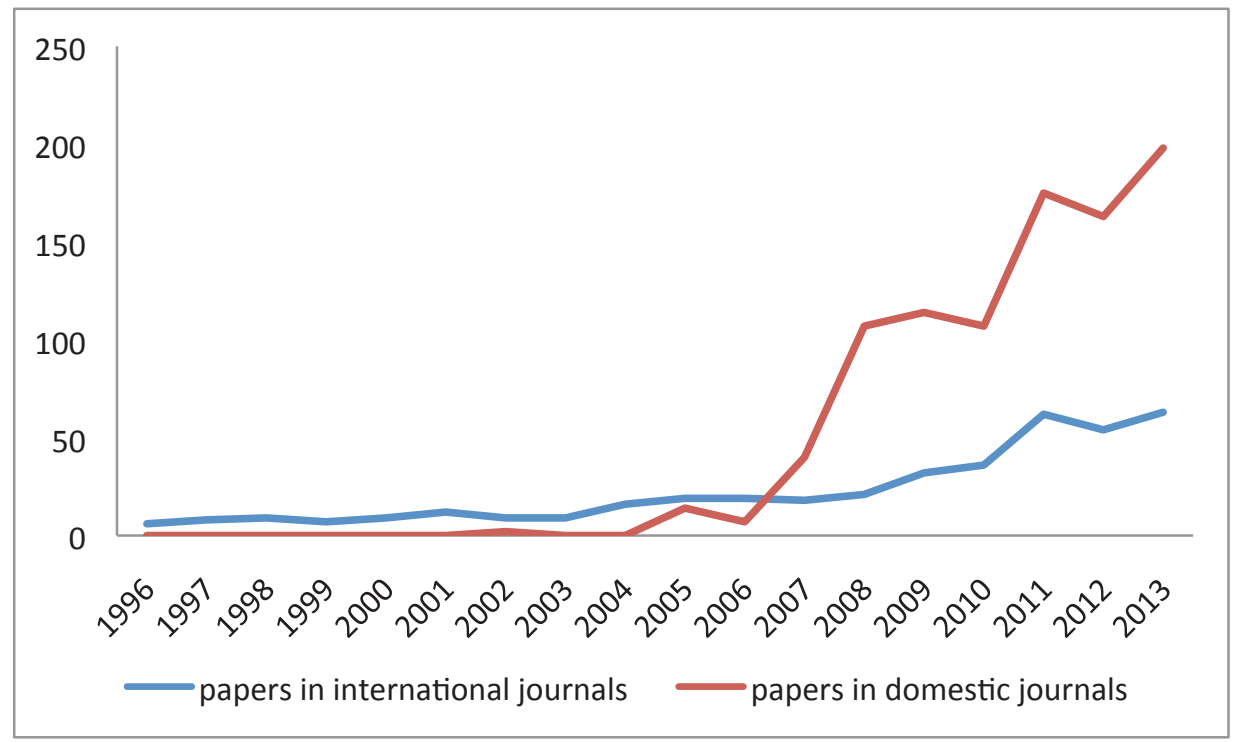

An analysis of the papers reveals that 409 or $31 \%$ of the total sample were published in 104 international journals, which shows that they were relatively scattered. The number of papers published per journal ranged from one to 20 , or an average of four papers per journal. A clearer picture is given when the real number of papers published in interna-

63 Mudge and Vauchez (n 48) 462.
${ }^{64}$ Black and Caron (n 30). 
tional journals is analysed. One or two papers (a total number of 87 papers) were published in more than a half or 66 journals altogether. On the other hand, a total number of 170 papers (42\%), ranging from 10 to 20 papers, were published in 12 international journals. These journals are an important communication channel for the exchange of ideas and research results of legal experts from CEE countries. The journals are European (Dutch, English, German and French), which could be an indicator of a gradual opening up towards other EU Member States.

The representation and accessibility of papers dealing with legal issues in relevant secondary international sources only provide the possibility of someone from the international academic community reading and citing them. The citation of papers, however, can show impact and potential visibility. Figure 3 shows the ratio of the total number of papers and citations in the sample, as well as the differences between the papers published in domestic, CEE and international journals.

Figure 3 The ratio between published papers and the number of citations received

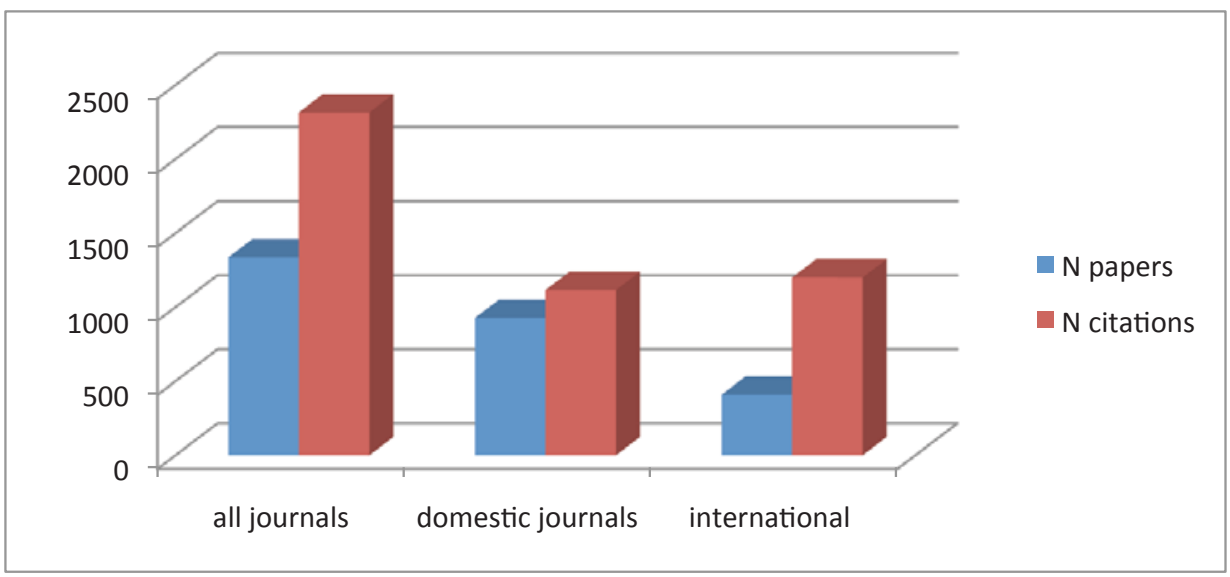

The purpose of the analysis of citations in this research is not to rank countries but to obtain orientation values for a better understanding of academic communication in the field of law. Shapiro and Pearse emphasise that citation analysis is now extensively used to study the history and structure of sciences and disciplines. ${ }^{65}$ This is because the literature lacks information that could be used as reference values for better interpretation of the results.

65 Shapiro and Pearse (n 34) 1485. 
The average number of citations received by papers in the sample $(\mathrm{N}=1,336)$, notwithstanding whether they were published in an international or domestic journal, was 1.73. This number is significantly higher than the average number of citations of papers published in domestic journals (1.2). The average number of citations for papers of authors in CEE countries published in international journals is 2.9.

Since a predominant number of legal papers were published in domestic legal journals, which could be explained by the specific role of national journals and the publication of legal papers in the national language, as already discussed above, we will consider these results in further detail. More precise data on the perception of legal papers published by experts from CEE countries, as measured by citations, is visible in Table 2.

Table 2 Number of papers and citations in domestic CEE law journals

\begin{tabular}{|l|l|c|c|c|}
\hline \multicolumn{2}{|c|}{ Journal publisher's country } & No of papers & $\begin{array}{c}\text { No of } \\
\text { citations }\end{array}$ & $\begin{array}{c}\text { Citations/ } \\
\text { paper }\end{array}$ \\
\hline \multirow{3}{*}{ Group A } & Poland & 30 & 19 & 0.63 \\
\cline { 2 - 5 } & Czech Republic & 5 & 0 & 0.00 \\
\cline { 2 - 5 } & Slovenia & 141 & 196 & 1.39 \\
\cline { 2 - 5 } & Hungary & 109 & 29 & 0.26 \\
\hline \multirow{3}{*}{ Group B } & Romania & 182 & 481 & 2.64 \\
\cline { 2 - 5 } & Croatia & 460 & 390 & 0.84 \\
\hline
\end{tabular}

Although the average number of citations per paper published in a domestic journal was 1.2 , it is noticeable that mostly Romanian and Slovenian papers contribute to this number. A deeper citation analysis could indicate the type of citations received, whether they were the self-citations of authors and journals or independent citations by colleagues outside the country. We can only assume that the number of domestic CEE journals could potentially affect the number of received citations.

Further analysis shows that the language barrier also contributes to citation numbers. Analysis of the language used in papers published in domestic journals shows that $46.5 \%$ of papers were published in a language outside the group of languages of the CEE countries. English dominates with $97 \%$ of papers. These papers acquired an average of 1.5 citations per paper. The average number of citations per paper published in domestic journals and written in a national CEE language was 0.9.

Papers published by CEE legal experts in international journals are significantly more visible. We can show in more detail the contribution 
of each researched country (Figure 4). The graph clearly shows that the countries from Group A are the biggest contributor to productivity in international journals. A possible explanation lies in the fact that out of the eight countries in the group only four have the opportunity to publish in domestic journals (Table 1). Countries from Group B have a significantly lower number of papers published in international journals, since two out of three countries (Croatia and Romania) have six out of the total number of 12 domestic journals. The countries in Group C did not have any domestic legal journals indexed in Scopus, and thus it is to be expected that papers from these countries were published predominantly in international journals. However, the results do not match the expectations.

Figure 4 Distribution of papers published in international journals by group of countries

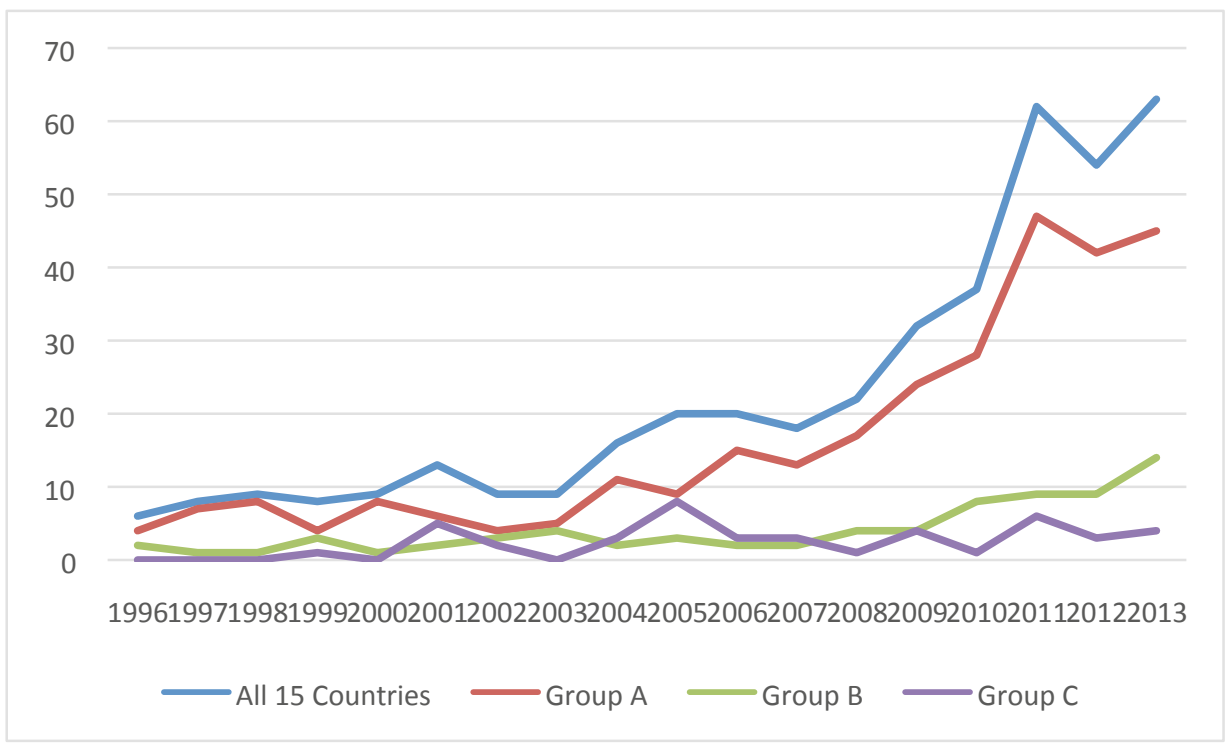

The visibility of papers published in international journals was measured by citations and is shown in Figure 5. The largest possible number of citations per paper was acquired by papers of authors from the countries in Group C (4.2). It is interesting to note that papers with co-authorship acquired the lowest citation scores in this group (1.6). The interpretation of the result, which shows that the countries in Group $\mathrm{C}$ acquired the highest overall citation score, calls for additional citation analysis, as well as for paper content analysis. Papers published by authors from countries in Group A in international journals acquired an average number of 2.9 citations, while the lowest average number of 
citations per paper was acquired by papers in the countries in Group B (2.48).

Figure 5 The ratio of productivity and citations of papers published in international journals

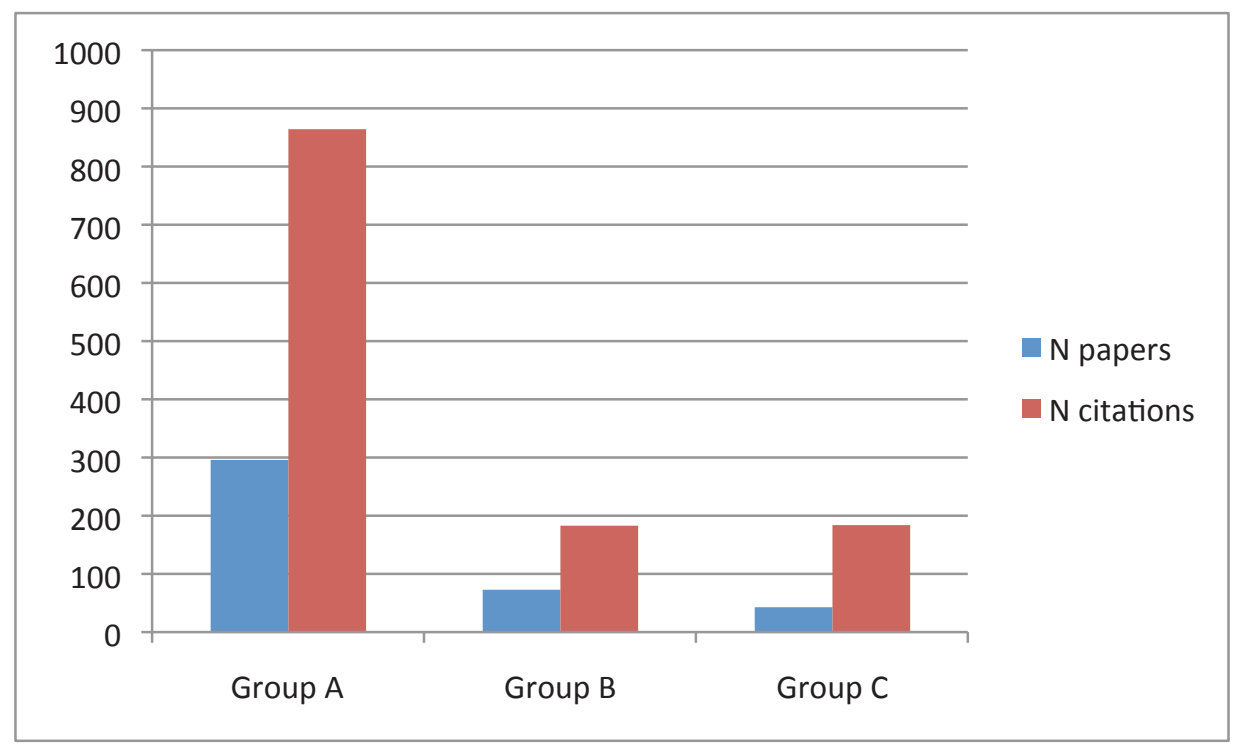

Analysis of the number of citations in terms of the number of authors in the field of law showed that the situation is similar to other academic fields. Namely, the average number of citations of papers written by a single author was 1.5, while the average number for papers with co-authorship was 2.1. Authors in the countries in Group A provided the most significant contribution to the average number of citations for papers with co-authorship, with an average of 2.6 citations per paper.

Information on the development of cooperation, as measured by the number of authors of papers in the field of law is important (Figure 6). The share of single authorship papers was 63\%, which is lower compared to the research result provided by Burman and Sheela in 2011, which showed that $70 \%$ of papers were single authorship papers. ${ }^{66}$ This information suggests that the publishing paradigm in the field of law, ie this aspect of academic communication in the field, has developed. This is also evident if observed over the whole period, as shown in Figure 6. Ginsburg and Miles connect the rise in academic collaboration with

66 JS Burman and M Sheela, 'Citation Analysis of Dissertations of Law Submitted to University of Delhi’ [2011] Library Philosophy and Practice $579<$ http://digitalcommons.unl.edu/ libphilprac/579> accessed 8 December 2018. 
scholarly specialisation. ${ }^{67}$ Determining the real reasons for the significant growth in the number of papers with co-authorship requires further detailed research.

Figure 6 Distribution of single authorship and co-authorship in the period 19962013

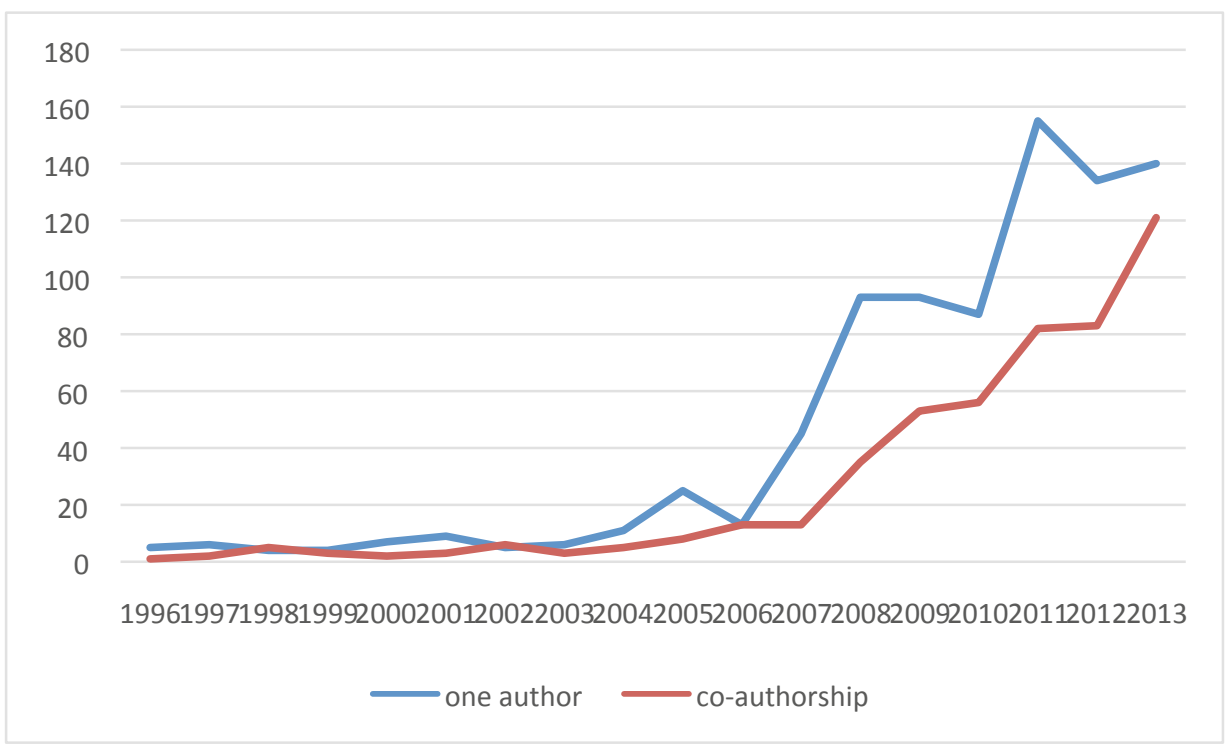

Although research results show that the language in which the paper was written is very important, it is evident that it is even more important whether the paper was published in an international or a domestic journal and whether one or more authors wrote it. A deeper analysis would be required for a more complete understanding of the citation scores. The precise meaning of the obtained results, ie whether we are talking about self-citation by authors and journals or whether the citations are independent of the journal publisher's country or, as emphasised by Shapiro and Pearse, whether the citation is responding directly to the article, relying on the article heavily, or merely mentioning it in a string citation, ${ }^{68}$ or whether the work is cited in a critical or negative manner, which would represent an exchange of ideas and potentially be an indicator of the advancement of knowledge, was not a part of this research. We have not analysed citations in terms of subject matter, although we consider it very important. Shapiro and Pearse have stressed

67 T Ginsburg and TJ Miles, 'Empiricism and the Rising Incidence of Co-authorship in Law' (2011) 5 University of Illinois Law Review 1785, 1785.

${ }^{68}$ Shapiro and Pearse (n 34) 1518. 
that certain areas, such as constitutional law, civil procedure, contracts, property, torts, and criminal law, have a large scholarly literature affording ample opportunities for being cited, while other areas have a smaller literature and less opportunity for citations that could earn articles in these fields inclusion on a 'most-cited' list. ${ }^{69}$ This sort of analysis, as well as co-citation analysis, is planned for future research.

\section{Conclusion}

Based on the results of a bibliometric analysis of papers written by legal experts from $15 \mathrm{CEE}$ countries published in journals indexed in Scopus in the period 1996-2013, the following conclusions on the visibility of scientific production and the contribution to the common European scientific research area are possible.

The biggest contribution to scholarly production (70\%) is, as expected, visible through publishing in national CEE law journals indexed in Scopus. This is predominantly because of the papers published in domestic law journals from four countries: Croatia, Romania, Slovenia and Hungary (98\%). It is important to note that the Baltic States and the EU candidate countries, 9 out of the 15 CEE countries, did not have law journals indexed by Scopus in the period 1996-2013, which influenced their potential availability and visibility.

A significantly lower number of papers (31\%) were published in the 104 international journals. A certain recognisability (42\% of papers) in the range of 10 to 20 papers per journal is present in 12 international journals that are dominated by European journals (Dutch, UK, German and French), which is a potential sign that the CEE countries are gradually opening up to other EU Member States.

The representation and availability of papers in the field of law in relevant multidisciplinary secondary international sources merely provides the opportunity for someone to read the papers and incorporate them, through citation, in new knowledge and ideas. The purpose of measuring the citation of papers of legal experts from CEE countries was not to rank them; it was to gain an insight into the availability and visibility of scientific activity in the field of law, which is an important area for EU Member States.

The average number of citations per paper in the research sample $(\mathrm{N}=1,336)$ was 1.73 . We have established that there is a significant difference in the average citation number of papers published in CEE or domestic journals (1.2 citations per paper) and those published in in-

${ }_{69}$ Shapiro and Pearse (n 34) 1488. 
ternational journals (2.9 citations per paper). This shows that citations are predominantly influenced by the language of papers, with English generally being the lingua franca of academic research, but also by the fact of whether the paper was published in a domestic or international journal. The average number of citations per paper published in English in domestic CEE journals was 1.5. Papers with co-authorship were more frequently cited than single authorship papers.

Most of the CEE countries are new Member States of the EU or still aspire to become Member States. In order to accomplish their integration into EU academic communication in the field of law, the visibility of CEE countries' legal scholars' work is crucial. Based on the analysis of this research, there are a few facts that contribute to the visibility of such papers: avoiding the language barrier by publishing in English; publishing in international journals on relevant issues of interest to the European and international academic and professional community; raising awareness of the importance of the international availability of published papers in domestic CEE law journals, etc. One of the conclusions of the research is an evident change of paradigm of authorship in the legal field, with a growing emphasis on papers with co-authorship.

With the aim of providing a greater availability, and better visibility and impact of papers published in domestic CEE journals, and thus their gradual integration into the common European space, editorial boards in the field of law could play an important role. In addition, we are aware of the fact that all 15 CEE countries have their own languages, which is extremely important for the profession, and the language and national identity of those countries. However, academic research by definition does not know such boundaries, and it is necessary to use the lingua franca.

This research is only an introduction to obtain an insight into the forms of scientific communication in the field of law in 15 European post-communist countries. For a more complete understanding of the meaning and integration of research in this field, more thorough quantitative and qualitative research should be carried out. For this reason, we are planning content analysis research on the published papers, an analysis of interviews with scholars, and additional comparative bibliometric analyses. 